\title{
Saffron (Crocus sativus) and its Active Ingredients: Role in the Prevention and Treatment of Disease
}

\author{
Arshad Husain Rahmani ${ }^{1 *}$, Amjad Ali Khan ${ }^{2}$, Yousef Homood Aldebasi ${ }^{3}$
}

\section{Arshad Husain Rahmani ${ }^{1 *}$, Amjad Ali Khan ${ }^{2}$, Yousef Homood Aldebasi ${ }^{3}$ 'Department of Medical Laboratories, College of Applied Medical Sciences, Qassim University, SAUDI ARABIA. ${ }^{2}$ Department of Basic Health Science, College of Applied Medical Sciences, Qassim University, SAUDI ARABIA. \\ ${ }^{3}$ Department of Optometry, College of Applied Medical Sciences, Qassim University, SAUDI ARABIA. \\ Correspondence \\ Dr. Arshad Husain Rahmani}

Department of Medical Laboratories, College of Applied Medical Sciences, Qassim University, SAUDI ARABIA.

E-mail: rehmani.arshad@gmail.com, ah.rahmani@qu.edu.sa

\section{History}

- Submission Date: 12-06-2017;

- Review completed: 28-07-2017.

- Accepted Date: 22-08-2017.

DOI : 10.5530/pj.2017.6.137

Article Available online

http://www.phcogj.com/v9/i6

\section{Copyright}

(C) 2017 Phcog.Net. This is an openaccess article distributed under the terms of the Creative Commons Attribution 4.0 International license.

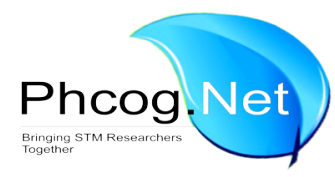

\begin{abstract}
Introduction: Crocus sativus is a member of iridaceae family and its use in health management is in practice since ancient time. Additionally, research based on clinical trials and animal models have advocates its role in disease cure without any severe adverse complications. The aim of this study is to summarize the study of saffron and its ingredients based on in vivo and in vitro and role in disease cure and prevention. Materials: This study was designed through the search engines such as Pub Med, Scopus and Google Scholar. The keywords used for the search were mainly focused on Saffron with health benefit and its therapeutics role in different diseases. Result: Saffron stigma is mixture of various components and recent studies have proven that saffron and its active ingredients play a key role in disease management. Moreover, clinical trials based study on the use of saffron and its individual components have confirmed the health promising effects. Conclusion: Although Saffron has potential role in the disease cure and prevention via modulation of anti-oxidant, anti-inflammatory, anti-tumour, anti-microbial and anti-diabetic activity. Furthermore, advanced research is needed to elaborate the role of saffron in health management and its mechanism of action in the modulation of biological activities.

Key words: Crocus sativus, Antioxidant, Anti-inflammatory, Anti-tumour activity, Toxicity level.
\end{abstract}

\section{INTRODUCTION}

Saffron is a spice of Crocus sativus (Saffron crocus) which belongs to the family of iridaceae ${ }^{1}$ and studies has advocates its role in diseases cure. Its health management properties have been discussed in traditional prescriptions including Chinese, Ayurveda and Unani medicines. Crocus sativus has been reported its role as sedative, expectorant, anti-asthma, emmenagogue, and adaptogenic agent. ${ }^{2}$ Different plant parts like peels, fruits, seeds and rind of Crocus sativus contain various biochemically active ingredients such as crocin, crocetin, and safranal in different proportion. These constituents have demonstrated the health promoting effect through the modulation of various biological and physiological processes.

The studies based on animal models and laboratory research has revealed that saffron has therapeutic implication in health management through anti-oxidant, anti-microbial, hepatoprotective and anti-tumour activity. Experiment finding confirmed that stigma ethanolic fraction showed the highest antioxidant activity possibly due to high content of phenolics and flavonoids ${ }^{3}$ and other studies have reported crocin role in inhibition of edema formation. ${ }^{4}$ Experiments have been performed to examine the mechanism of chemopreventive activity of this spice and the result of such study has revealed that saffron notably reduces the increased number and incidence of hepatic dyschromatic nodules induced by diethylnitrosamine. ${ }^{5}$

Earlier studies reported that saffron is safe at various doses and did not show any severe side effects. Saffron aqua extract and pure crocin were safely tolerated in patients with schizophrenia. ${ }^{6}$ Study bases on evaluating the lactating toxicity and histological studies confirmed that saffron did not show any toxic effect on liver.7 This review is aimed to discuss the pharmalogical activities of saffron as an antioxidant, antiinflammatory, hepato-protective, cardiprotective, anti-diabetic and anti-tumour activity along with safe dosage levels based on clinical studies.

\section{Chief ingredients of saffron}

Saffron stigma is mixture of various components and such constituents have therapeutics importance in the health management through the modulation of various biological pathways. Saffron stigmas contain numerous volatile compounds and ingredients including crocin, picrocrocin and safranal and these compounds are accountable for color, taste and odor of saffron respectively. ${ }^{8-11}$ Safranal is the major coloring constituent of saffron, so saffron is used as a flavoring and coloring agent. ${ }^{12}$ In addition to these compounds, 
saffron also contains little amounts of other pigments like anthocyanin, $\alpha$-carotene, $\beta$ - carotene, and zegxantin. ${ }^{13}$

\section{Possible mechanism of action of saffron and its ingredient in diseases prevention}

The exact mechanism by which saffron and its constituents demonstrate the therapeutic role in diseases prevention is yet to be fully elucidated. Laboratory based research has revealed that saffron constituents modulate the activity of various enzymes involved in free radical scavenging. Moreover, these components reduce the lipid peroxidation and enhance the antioxidant status. Stigma ethanolic fraction of saffron showed the highest antioxidant activity that might be recognized due to the presence of phenolics and flavonoids. ${ }^{3-14}$ Other experimental data advocates that saffron helps in reduction of inflammation through the inhibition of cycoloxygenase enzyme activity. Saffron alleviates neuropathic pain via reduction of proinflammatory cytokines, antioxidant activity and apoptotic pathways ${ }^{15}$ and in vitro study has revealed that crocin possess dual inhibitory activity against COX-1 and COX-2 enzymes. ${ }^{4}$ Saffron also shows a very important role in the tumour prevention and some findings advocate that saffron and its constituents induce apoptosis or change the ratio of bcl2/bax and finally inhibiting the development and progression of tumour.

\section{$\mathrm{LD}_{50}$, Safety and toxicity level of saffron and its ingredient}

A study based on mice model revealed that $\mathrm{LD}_{50}$ value of saffron was $4120 \pm 556 \mathrm{mg} / \mathrm{kg}^{7}$ and correspondingly, $\mathrm{LD}_{50}$ of safranal, a constituent of saffron is reported to be $1.48 \mathrm{~mL} / \mathrm{kg}$ and $1.88 \mathrm{~mL} / \mathrm{kg}$ in male and female mice respectively. ${ }^{16}$ Other study based on mice models have reported that, $\mathrm{LD}_{50}$ values of saffron stigma and petal extracts were 1.6 and $6 \mathrm{~g} / \mathrm{kg}$ respectively in. ${ }^{17}$ In addition to this, saffron aqua extract and crocin have been found to be safely tolerated in patients with schizophrenia. ${ }^{6}$ Safranal, an ingredient of saffron was less-toxic in acute intraperitoneal route and non-toxic in acute oral administration in mice and rats. ${ }^{16}$ However, in sub acute toxicity tests, safranal showed alterations in hematological and biochemical parameters. ${ }^{16}$ Saffron tablets have proven that it showed a little change in hematological as well as biochemical parameters but such changes were within normal ranges. ${ }^{18}$ Rat model based study for sub-acute toxicity revealed that saffron showed increased survival and no mortality rates at a dose of $10 \mathrm{mg} / \mathrm{kg} .{ }^{19}$ Saffron has confirmed it did not show toxic effect on liver whereas histo-pathological changes were noticed in the neonate kidneys. ${ }^{7}$ Moreover, earlier study has reported that the injection dose between $1.2 \mathrm{~g}$ and $2 \mathrm{~g}$ of saffron may cause some complications including nausea, vomiting and, diarrhea. ${ }^{20}$

\section{Clinical studies on saffron and their constituent}

Clinical trials based on the use of saffron and its individual components have confirmed the health promising effects. Double-blind study performed on patients, who were randomly allocated to receive saffron or imipramine capsule, have revealed that the dose of saffron is efficiently similar to imipramine in the treatment of mild to moderate depression. ${ }^{21}$ In another similar pilot study, forty adult outpatients were randomly assigned to get capsules of saffron or fluoxetine and the results revealed that fluoxetine is similar in the treatment of mild to moderate depression. ${ }^{22}$ Schizophrenic cases were used to study the safety and tolerability of saffron aqueous extract and crocin and the results of the study have revealed that none of the patients showed any severe side effects. ${ }^{6}$ WBC count was found to increase within a limited range in patients that getting saffron aqua extract and those patients did not show any clinical significance. ${ }^{6}$ Randomized, double-blind, placebo-controlled study design consisting of one-month treatment of crocin tablets have confirmed that no major unfavorable effect was noticed during the trial. ${ }^{23}$ In a similar study performed on double-blind, placebo-controlled patients getting a capsule of saffron or placebo capsule for a six-week study. Crocus sativus showed significantly better outcome on the Hamilton depression rating scale and there were no significant differences observed in the two groups in terms of the side effects. ${ }^{24}$

\section{Pharmalogical activities of saffron \\ Anti-oxidant activity}

The imbalance between reactive oxygen species (ROS) production and antioxidant level is directly linked to the pathogenesis of diseases. The enhancement of antioxidant level or reduction of reactive species level is maintained through antioxidant properties of plants or their derivatives. Natural products or derivatives of medicinal plants usually contain various components including flavonoids which show a pivotal role as antioxidants and free radicals scavenging activity. Numerous studies based on in vivo and in vitro have confirmed that Crocus sativus has a significant antioxidant activity Table 1 .

Antioxidant activity of saffron has been observed in extract of stigma and such extract shows role in the reduction of chlorophyll damage, lipid peroxidation, and protein oxidation. ${ }^{3}$ Similarly, other finding has confirmed that saffron stigma contains superior antioxidant activity. ${ }^{14}$ Earlier findings have demonstrated that active and inactive constituents of saffron extract have high antioxidant activity ${ }^{25}$ and saffron petal extract showed antioxidant activity. ${ }^{26}$ Another study demonstrated that constituent of saffron such as crocin has a potent antioxidant activity. ${ }^{27}$ Lebanon based finding demonstrated that saffron notably decreased lipid peroxidation as well increased superoxide dismutase activity when compared to control group. ${ }^{28}$ Crocin, constituent of saffron showed role in the inhibition of lipid peroxidation and restored SOD activity ${ }^{29}$ and stigmas of Crocus sativus contains more antioxidant activity as compared to tomatoes and carrots. ${ }^{30}$

\section{Anti-inflammatory effect}

Natural product based treatments for migraine, pain, inflammation and arthritis are very popular in traditional medicine due to easily availability and almost no side effects properties. In this regard, C. sativus has also proven its role as an anti-inflammatory Table 1. A study was performed on mice models to evaluate its anti-inflammatory activity and the results revealed that extracts of stigma and petal of saffron showed anti-inflammatory activity. ${ }^{31}$ In a parallel study results demonstrated that ingredients of saffron such as crocin and safranal suppressed inflammatory pain response as well and decreased the number of neutrophils. ${ }^{32}$

\section{Anti-microbial activity}

Multi-drug resistant microorganism to antibiotics is alarmingly rising worldwide. As a treatment module against microorganism, natural products or derivatives of medicinal plants represent a symbol of good source of antimicrobial agents without any adverse side effect. Different parts of Crocus sativus, such as stamen and corolla have been employed as a good source of antimicrobial agents. ${ }^{33}$ Extracts of Crocus sativus against various bacterial strains have confirmed an improved activity against bacteria and fungi used as test organisms. ${ }^{34}$ In addition, antibacterial effects of other blends like aqueous, ethanolic and methanolic extracts of petal were measured against the foodborne pathogens and the results have confirmed that such extracts show antimicrobial activity against most of the pathogenic bacteria. ${ }^{35}$

\section{Hepatoprotective effect}

Parts of medicinal plant like flowers, leaves, stem, roots and seeds have been found to possess a good hepato-protective activity. In this vista, 
Rahmani et al:: Pharmacological activities of Saffron and its active constituents.

Table 1: Pharmalogical activities of saffron and its constituents.

\begin{tabular}{|c|c|c|c|}
\hline Reference & Biological activity & Aim of study & Finding /Outcome \\
\hline [14] & Antioxidant & $\begin{array}{l}\text { Evaluation of antioxidant activity of } \\
\text { stigmas extract }\end{array}$ & Saffron stigma showed antioxidant activity. \\
\hline [26] & Antioxidant & Measurement of antioxidant & Antioxidant activity has been observed. \\
\hline [32] & Anti-inflammatory & $\begin{array}{l}\text { Effects of crocin, safranal on local } \\
\text { inflammation }\end{array}$ & $\begin{array}{l}\text { Study finding reported that crocin and safranal showed role in the } \\
\text { suppression of inflammatory pain responses and decreased the } \\
\text { number of neutrophils. }\end{array}$ \\
\hline [4] & Anti-inflammatory & Anti-inflammatory effects of crocin & $\begin{array}{c}\text { Crocin, a constituent showed anti-inflammatory effects and } \\
\text { modulate inflammatory processes. }\end{array}$ \\
\hline [33] & Antibacterial & C. sativus extract tested against bacteria. & Strong activity of against bacteria and fungi was noted. \\
\hline [36] & Hepatoprotective & $\begin{array}{l}\text { Evaluation of protective effects of extract } \\
\text { against hepatotoxicity }\end{array}$ & Finding demonstrated that petals ameliorate acute liver injury. \\
\hline [40] & $\begin{array}{l}\text { Protective effect against } \\
\text { nephrotoxicity }\end{array}$ & Effect of safranal against nephrotoxicity & Safranal has a protective effect against nephrotoxicity. \\
\hline [42] & Cardio-protective & $\begin{array}{l}\text { Cardio-protective effect of saffron and } \\
\text { safranal. }\end{array}$ & $\begin{array}{l}\text { Result revealed that myocardial injury preserved nearly normal } \\
\text { tissue architecture with saffron or safranal pretreatment. }\end{array}$ \\
\hline [49] & $\begin{array}{l}\text { Inhibitory action on } \\
\text { AChE }\end{array}$ & $\begin{array}{l}\text { Inhibitory action on } \mathrm{AChE} \text { via saffron } \\
\text { extract and its constituents. }\end{array}$ & $\begin{array}{l}\text { Result indicated that Saffron extract showed moderate AChE } \\
\text { inhibitory activity. }\end{array}$ \\
\hline [53] & Anti-hyperglycemic & $\begin{array}{l}\text { Saffron, crocin and safranal effects on the } \\
\text { blood levels of fasting glucose, HbAlc and } \\
\text { liver/kidney function tests }\end{array}$ & $\begin{array}{l}\text { Result demonstrated that saffron extract, crocin and safranal } \\
\text { significantly reduced the fasting blood glucose levels but } \\
\text { significantly increased the blood insulin levels in the diabetic rats } \\
\text { compared with the control diabetic rats. }\end{array}$ \\
\hline [56] & $\begin{array}{l}\text { Anti-obesity and } \\
\text { anorectic }\end{array}$ & $\begin{array}{l}\text { Effects of saffron and crocin on body } \\
\text { weight, food intake and blood leptin levels. }\end{array}$ & $\begin{array}{l}\text { Result concluded that saffron has anti-obesity and anorectic effects } \\
\text { and lowered leptin levels. }\end{array}$ \\
\hline [57] & Anti-obesity & $\begin{array}{c}\text { Evaluation of anti-obesity effects of saffron } \\
\text { and crocin }\end{array}$ & $\begin{array}{l}\text { Result showed that saffron extract significantly decreased food } \\
\text { consumption in obese rats. Furthermore, crocin showed a } \\
\text { significant decrease on rate of body weight gain. }\end{array}$ \\
\hline [58] & Aphrodisiac activities & $\begin{array}{l}\text { Aphrodisiac activities of stigma and } \\
\text { safranal and crocin. }\end{array}$ & $\begin{array}{l}\text { The study results revealed that aphrodisiac activity of saffron } \\
\text { extract and its constituent crocin. }\end{array}$ \\
\hline$[60]$ & Anxiolytic properties & $\begin{array}{l}\text { Evaluation of anxiolytic and hypnotic effect } \\
\text { of saffron extract, crocin and safranal. }\end{array}$ & $\begin{array}{l}\text { Results confirmed safranal at higher doses demonstrated anxiolytic } \\
\text { effects whereas crocin did not show anxiolytic properties. }\end{array}$ \\
\hline$[62]$ & Immuno-stimulatory & $\begin{array}{l}\text { Effects of saffron petal extract on blood } \\
\text { parameters and immune system }\end{array}$ & Saffron petal extract use causes an increase in antibody response \\
\hline [64] & Anticonvulsant & $\begin{array}{l}\text { Evaluation of anticonvulsant of safranal } \\
\text { and crocin }\end{array}$ & $\begin{array}{l}\text { Finding confirmed that safranal reduced the seizure duration, } \\
\text { delayed the onset of tonic convulsions }\end{array}$ \\
\hline
\end{tabular}

saffron has also been checked for the liver ailments which possible improve or decrease various liver enzymes activity Table 1. Increases level of ALT, AST and bilirubin level and lowering total protein and albumin production was observed in acetaminophen treated rat models whereas pretreatment of rats with Crocus sativus petals extract resists this rise of aminotransferases and bilirubin levels and normalize the level of serum proteins as compared to disease control. ${ }^{36}$ Results of findings have confirmed that saffron and honey showed role in the reduction of toxic effects of aluminum chloride and alleviate its disrupting effects at biochemical and molecular levels ${ }^{37}$ and other results have confirmed that this ingredient of saffron definitely reduces the oxidative stress and prevents hepatotoxicity. ${ }^{38}$

\section{Nephrotoxicity effect}

In this regard, crocin from saffron has also been tried by some researchers to survey its role against renal problems. It has been observed that this compound obstructs the development of acute renal failure and oxidative stress in experimental animals. ${ }^{39}$ In a parallel study, safranal has been found to possess a protective effect against nephrotoxicity ${ }^{40,41}$

\section{Cardio-protective effect}

Several medicinal plants have been used for the treatment of heart ailments since ancient times. In this vista, saffron and its constituents have also supported the evidences of cardio-protective effects. Rat model based study has confirmed that whole saffron pretreatment or its individual constituents such as safranal pretreatment considerably decrease the serum LDH and CK-MB level, as well as myocardial lipid peroxidation as compared to isoproterenol - induced animals. ${ }^{42}$ Crocin, an ingredient of saffron revealed its protective effects of cardio-toxicity through reducing lipid peroxidation as well as alleviating apoptosis. ${ }^{43}$

In a similar study based on rat models, it was concluded that crocin improves toxic effects of diazinon through decreasing lipid peroxidation and restoring altered contractile and relaxant responses in aorta. ${ }^{44}$ The cardio-protective effect of saffron active constituents including crocin has been confirmed through regulation of oxidative stress. ${ }^{45}$ The finding concluded that Crocus sativus perfused during electrolysis might trap radical oxygen species and significantly improve myocardial function. ${ }^{46}$ 


\section{Neuroprotective effect}

Crocin has been examined for its role against cytotoxicity effects. In this scenario, it has been observed that pretreatment of groups or cells with crocin protected them from acrylamide-induced apoptosis via inhibition of intracellular ROS production. ${ }^{47}$ Furthermore, pretreatment of numerous dopaminergic cells of substantia nigra pars compacta from mice and retina of Parkinsonian cases were investigated for acetylcholinesterase inhibitory activity by saffron and it was observed that saffron ingredient, crocin actively exhibits this activity ${ }^{48,49}$ Crocin also attenuates the learning and memory impairment in streptozotocin injected animal groups. ${ }^{50}$

\section{Anti-diabetic activity}

The extract of saffron has been found to be effective in reducing fasting blood glucose in mild diabetic and in severely diabetic rats. ${ }^{51}$ Other finding demonstrated that saffron with dose of 40 and $80 \mathrm{mg} / \mathrm{kg}$ significantly increased body weight and serum TNF- $\alpha$ and decreased blood glucose levels and glycosylated serum protein levels. ${ }^{52}$ In one more study, it was found that methanolic extract of saffron, crocin and safranal notably reduce the fasting blood glucose and $\mathrm{HbA} 1 \mathrm{c}$ levels. ${ }^{53}$ Similarly, further study indicates that crocin, was found to significantly reduce the blood glucose level. ${ }^{54}$ Oral administration of saffron extract was found to significantly increase the body weight and regulates the serum insulin level in diabetic rats as compared to disease control groups. ${ }^{55}$

\section{Anti-obesity effect}

Earlier investigations concluded that Saffron showed anti-obesity and anorectic effects in the obese rat models. Moreover, its property of reducing the leptin level in obese cases indicates that saffron reduces fat mass and increases insulin sensitivity. ${ }^{56}$ In an experimental protocol, it was performed to assess the anti-obesity effects of ethanolic extracts of saffron and crocin. Results of this study demonstrated that saffron extract notably decrease the food consumption by obese rats as compared to control groups. Furthermore, crocin showed a noteworthy decrease on rate of body weight gain, total fat deposition and regulates the weight ratio of epididymal fat to body. ${ }^{57}$

\section{Aphrodisiac activities}

Saffron also plays an important role in improving the fertility and increases the libido when consumed. Results have revealed that crocin and its aqueous extract particularly at doses of $160-320 \mathrm{mg} / \mathrm{kg}$ b.w. increased mounting and erection frequency behaviors and in addition to this reduced ejaculation, intromission and mount latency parameters. ${ }^{58}$

\section{Anxiolytic activity}

A study was performed to examine whether or not crocin, a major constituents of saffron hold anxiolytic activities. Either crocin which did not influence animal's motor activity or diazepam notably increased the latency to enter the dark compartment. The study designates that treatment with chief ingredients of Crocus sativus $L$. induces anxiety relieving effects in the rat ${ }^{59}$ and safranal at higher dosage demonstrated anxiolytic effects and furthermore, safranal increased the total sleep time dose dependence. $^{60}$

\section{Immunomodulatory effect}

Earlier finding has supported the role of saffron in improving the immune system and it was shown that saffron increased the IgG level and decreased the IgM level as compared with the baseline and placebo groups. ${ }^{61}$ In addition to this, it increases the percentage of monocytes as compared with placebo. ${ }^{61}$ Other study concluded that saffron petal extract causes an increase in antibody response without any alteration in hematological parameters or histology of spleen. ${ }^{62}$

\section{Effect on retinal function}

Results have positively confirmed from a study that analogue of Crocus sativus were found to significantly increase the blood flow in the retina and choroid and enhance the retinal function recovery. ${ }^{63}$

\section{Anticonvulsant effect}

Experiments based on mice were performed to evaluate the anticonvulsant activities of safranal and crocin and the results indicate that safranal reduced the seizure duration, delayed the onset of convulsions as well as

Table 2: Anti-tumour activity of saffron and its ingredients.

\begin{tabular}{|c|c|c|c|}
\hline Reference & Tumor/Cell type & Aim of study & Finding \\
\hline$[68]$ & $\begin{array}{l}\text { Sarcoma-180, Ehrlich ascites } \\
\text { Carcinoma and Dalton's } \\
\text { lymphoma }\end{array}$ & Antitumor activity of saffron & $\begin{array}{l}\text { Study finding demonstrated that oral administration of extract } \\
\text { increased the life span of S-180, EAC, DLA tumour bearing mice }\end{array}$ \\
\hline$[70]$ & Transitional cell carcinoma & Cytotoxic effect of extract of saffron & $\begin{array}{l}\text { Study concluded that saffron extract has inhibitory effects on the } \\
\text { growth of both TCC as well as normal cell lines. }\end{array}$ \\
\hline$[72]$ & Colorectal cancer & $\begin{array}{l}\text { Anti-proliferative effects of Crocus } \\
\text { sativus extract and crocin }\end{array}$ & $\begin{array}{l}\text { Data from this study demonstrated that Crocus sativus extract and } \\
\text { crocin, significantly inhibited the growth of colorectal cancer cells }\end{array}$ \\
\hline$[74]$ & Hepatocarcinoma & Antiproliferative Effects & $\begin{array}{l}\text { Study finding revealed that telomerase activity of HepG2 cells decreases } \\
\text { after treatment with crocin }\end{array}$ \\
\hline$[75]$ & $\begin{array}{l}\text { Malignant and nonmalignant } \\
\text { prostate cancer cell }\end{array}$ & $\begin{array}{l}\text { Antiproliferative effects of saffron } \\
\text { extract and crocin }\end{array}$ & $\begin{array}{l}\text { Based on result study concluded that both saffron extract as well as } \\
\text { crocin can inhibit cell proliferation and arrest cell cycle progression }\end{array}$ \\
\hline$[77]$ & Prostate cancer & Cytotoxic and apoptosis induction & $\begin{array}{l}\text { Finding based on result demonstrated a prostate cancer cell line to be } \\
\text { highly sensitive to safranal-mediated growth inhibition and apoptotic } \\
\text { cell death. }\end{array}$ \\
\hline$[76]$ & Skin carcinoma & $\begin{array}{l}\text { Chemopreventive effect of aqueous } \\
\text { saffron }\end{array}$ & $\begin{array}{l}\text { Study result concluded that saffron inhibits skin carcinoma in mice } \\
\text { when treated early. }\end{array}$ \\
\hline$[77]$ & Lung cancer cells & $\begin{array}{l}\text { Potential of saffron to induce } \\
\text { cytotoxic and apoptotic effects }\end{array}$ & $\begin{array}{l}\text { Finding demonstrated that proliferation of the A549 cells was } \\
\text { decreased after treatment with saffron }\end{array}$ \\
\hline$[79]$ & Human pancreatic cancer & $\begin{array}{l}\text { Designed to elucidate apoptosis } \\
\text { induction by crocin }\end{array}$ & Crocin induced apoptosis and G1-phase cell cycle arrest \\
\hline
\end{tabular}


Rahmani et al:: Pharmacological activities of Saffron and its active constituents.

protected mice from death. ${ }^{64}$ This study further investigated that crocin did not show this anticonvulsant activity at all. ${ }^{64}$

\section{Anti-tumour activity}

It is very well known that medicinal plants such as curcumin, ginger, carica papaya and black seed have therapeutic role in the management of numerous diseases including tumour. ${ }^{65-67}$ Saffron and its active constituents perform an important role in the inhibition of tumour development and progression Table 2. In this regard, numerous findings based on animal models confirmed that saffron plays a role in prevention of various types of tumour. Saffron extract via oral administration show increased life span of sarcoma -180, Ehrlich ascites Carcinoma and Dalton's lymphoma ascites tumour bearing mice. ${ }^{68}$ Earlier findings reported that crocetin, an ingredient of saffron intensively reverted back the pathological changes noticed in cancerous animals ${ }^{69}$ and other finding concluded that saffron aqueous extract shows inhibitory effects on the growth of both transitional cell carcinoma and normal cell lines. ${ }^{70}$

Either intraperitoneal administration of Nigella sativa or oral administration of saffron after subcutaneous administration of MCA showed restriction of tumor incidence as compared with \% MCA-treated controls. ${ }^{71}$ Anti-proliferative effects of saffron extract and pure crocin was examined on colorectal cancer cell lines. The result of this study revealed that both the extracts, significantly inhibited the growth of colorectal cancer cells whereas it did not affect normal cells. ${ }^{72}$ Furthermore, cytotoxicity and DNA-adduct formation of microsomes activated by aflatoxin $\mathrm{B} 1$ in the fibroblast cells were noticeably inhibited by crocetin pretreatment. ${ }^{73} \mathrm{~A}$ finding showed that telomerase activity of HepG2 cells decreases after treatment with ingredient of saffron including crocin $^{74}$ Antiproliferative effects of saffron extract and individual constituent like crocin was evaluated on various malignant and nonmalignant prostate cancer cell lines. Results based on these findings reported that crocin reduced proliferation in all malignant cells whereas nonmalignant cells were not affected at all. ${ }^{75}$

In addition to this, another experiment was performed to investigate the chemopreventive effect of aqueous saffron. The result of the studies reported that saffron ingestion inhibited the formation of skin papillomas and simultaneously reduced their size in animals. ${ }^{76}$ Furthermore, investigation has been done on the role of saffron to induce cytotoxic and apoptotic effects in lung cancer cells. The results of the study have revealed that proliferation of such cells was decreased after treatment of saffron in a dose- and time-dependent manner. ${ }^{77}$ Moreover, saffron induced morphological changes, decreases percentage of some viable cells, and induce apoptosis. ${ }^{77}$ Result of study revealed that crocin inhibited cell proliferation and induced apoptosis and cell cycle arrest at $G_{0} / G_{1}$ phase. Moreover, crocin inhibited the tumor weight as well as size of xenografts in nude mice. In addition to this Bcl-2 expression was inhibited and Bax expression in xenografts was increased. ${ }^{78}$

In another important study, performed on human pancreatic cancer cell line to elucidate apoptosis induction by crocin and the results of this study reported that crocin induced apoptosis and G1-phase cell cycle arrest. $^{79}$

\section{CONCLUSION}

These days the popularity of alternative medicines based treatment is gaining much interest in the health practice. Saffron has shown its role in disease prevention and treatment and its importance in disease cure have been documented. Moreover, it is believed to be a safe and its adverse effect was not noticed at various doses. In addition, mortality was not noticed in animal model experiments at different dosage of individual ingredient of saffron. The role of saffron including crocin and crocetin in the management of numerous diseases has proven via modulation of various physiological and biochemical pathways. Saffron has also been reported to exhibit an anti-tumour effect through inactivation or activation of different molecular cascades. Research based on animal models and clinical trials are further needed to expand the understanding of saffron and its constituent's role in diseases prevention.

\section{ACKNOWLEDGMENT}

The authors are thankful to College of Applied Medical Sciences, Qassim University, Saudi Arabia for providing the facility to design this work.

\section{CONFLICT OF INTEREST}

There is no conflict of interest.

\section{ABBREVIATION USED}

COX: Cyclooxygenase; ROS: Reactive Oxygen Species; ALP: Alkaline Phosphatase; TCC: Transitional Cell Carcinoma; SOD: Superoxide dismutase; TNF - $\boldsymbol{\alpha}$ : Tumor necrosis factor; LD: Lethal dose.

\section{REFERENCES}

1. Kamalipour M, Akhondzadeh S. Cardiovascular Effects of Saffron: An EvidenceBased Review. J Tehran Heart Cent. 2011;6(2):59-61.

2. Gohari AR, Saeidnia S, Mahmoodabadi MK. An overview on saffron, phytochemicals, and medicinal properties. Pharmacogn Rev. 2013;7(13):61-6.

3. Baba SA, Malik AH, Wani ZA, Mohiuddin T, Shah Z, Abbas N, et al. Phytochemical analysis and antioxidant activity of different tissue types of Crocus sativus and oxidative stress alleviating potential of saffron extract in plants, bacteria, and yeast. S Afr J Bot. 2015;99:80-7.

4. Xu GL, Li G, Ma HP, Zhong H, Liu F, Ao GZ. Preventive effect of crocin in inflamed animals and in LPS-challenged RAW 264.7 cells. J Agric Food Chem. 2009;57(18):8325-30

5. Amin A, Hamza AA, Bajbouj K, Ashraf SS, Daoud S. Saffron: a potential candidate for a novel anticancer drug against hepatocellular carcinoma. Hepatology. 2011;54(3):857-67

6. Mousavi B, Bathaie SZ, Fadai F, Ashtari Z, Beigi NA, Farhang S, et al. Safety evaluation of saffron stigma (Crocus sativus L.) aqueous extract and crocin in patients with schizophreniaAvicenna J Phytomed. 2015;5(5):413-9.

7. Bahmani M, Rafieian M, Baradaran A, Rafieian S, Rafieian-Kopaei M. Nephrotoxicity and hepatotoxicity evaluation of Crocus sativus stigmas in neonates of nursing mice. J Nephropathol. 2014;3(2):81-5.

8. Melnyk JP, Wang S, Marcone MF. Chemical and biological properties of the world's most expensive spice:Saffron. Food Res Int. 2010;43(8):1981-9.

9. Rezaee R, Hosseinzadeh H. Safranal, from an aromatic natural product to a rewarding pharmacological agent. Iran J Basic Med Sci. 2013;16(1):12-26.

10. Bathaie SZ, Mousavi SZ. New applications and mechanisms of action of saffron and its important ingredients. Crit Rev Food Sci Nutr. 2010;50(8):761-86.

11. Samarghandian S, Borji A. Anticarcinogenic effect of saffron (Crocus sativus L.) and its ingredients. Pharmacog Res. 2014;6(2):99-107

12. Gohari AR, Saeidnia S, Mahmoodabadi MK. An overview on saffron, phytochemicals, and medicinal properties. Pharmacogn. Rev. 2013;7(13):61

13. Lage M, Cantrell C. Quantification of saffron (Crocus sativus L.) metabolites crocins, picrocrocin and safranal for quality determination of the spice grown under different environmental Moroccan conditions. Sci Hortic. 2009;121(3):366-73

14. Karimi E, Oskoueian E, Hendra R, Jaafar HZ, Evaluation of Crocus sativus L. stigma phenolic and flavonoid compounds and its antioxidant activity. Molecules. 2010;15(9):6244-56

15. Amin B, Abnous K, Motamedshariaty V, Hosseinzadeh $\mathrm{H}$. Attenuation of oxidative stress, inflammation and apoptosis by ethanolic and aqueous extracts of Crocus sativus L. stigma after chronic constriction injury of rats. An Acad Bras Cienc. 2014;86(4):1821-32.

16. Hosseinzadeh H, Shakib SS, Sameni AK, Taghiabadi E. Acute and Subacute Toxicity of Safranal, a Constituent of Saffron, in Mice and Rats Iran J Pharm Res. 2013;12(1):93-9.

17. Karimi GH, Taiebi N, Hosseinzadeh H, Shirzad F. Evaluation of subacute toxicity of aqueous extract of Crocus sativus L. stigma and petal in rats. J. Med. Plants. 2004;3:29-35

18. Modaghegh MH, Shahabian M, Esmaeili HA, Rajbai O, Hosseinzadeh H. Safety evaluation of saffron (Crocus sativus) tablets in healthy volunteers. Phytomedicine. 2008;15(12):1032-7.

19. Ziaee T, Razavi BM, Hosseinzadeh H. Saffron Reduced Toxic Effects of its Constituent, Safranal, in Acute and Subacute Toxicities in Rats. J Nat Pharm 
Rahmani et al:: Pharmacological activities of Saffron and its active constituents.

Prod. 2014;9(1):3-8.

20. Schmidt M, Betti G, Hensel A. Saffron in phytotherapy: pharmacology and clinical uses. Wien Med Wochenschr. 2007;157(13-14):315-9.

21. Akhondzadeh S, Fallah-Pour H, Afkham K, Jamshidi A, Khalighi-Cigaroudi F Comparison of Crocus sativus $\mathrm{L}$. and imipramine in the treatment of mild to moderate depression: A pilot double-blind randomized trial [ISRCTN45683816] BMC Complement Altern Med. 2004;4(1):12.

22. Noorbala AA, Akhondzadeh S, Tahmacebi-Pour N, Jamshidi AH. Hydro-alcoholic extract of Crocus sativus $L$. versus fluoxetine in the treatment of mild to moderate depression: a double-blind, randomized pilot trial. J Ethnopharmacol. 2005;97(2):281-4

23. Mohamadpour AH, Ayati Z, Parizadeh MR, Rajbai O, Hosseinzadeh H. Safety Evaluation of Crocin (a constituent of saffron) Tablets in Healthy Volunteers. Iran J Basic Med Sci. 2013;16(1):39-46.

24. Moshiri E, Basti AA, Noorbala AA, Jamshidi AH, Hesameddin AS, Akhondzadeh S. Crocus sativus L. (petal) in the treatment of mild-to-moderate depression: a double-blind, randomized and placebo-controlled trial. Phytomedicine. 2006; 13(9-10):607-11

25. Assimopoulou AN, Sinakos Z, Papageorgiou VP. Radical scavenging activity of Crocus sativus L. extract and its bioactive constituents. Phytother Res. 2005; 19(11):997-1000

26. Goli SA, Mokhtari F, Rahimmalek M. Phenolic compounds and antioxidant activity from Saffron (Crocus sativus L.) Petal. J Agric Sci. 2012;4(10):175-81.

27. Asdaq SM, Inamdar MN. Crocus sativus (saffron) and its constituent, crocin, as hypolipidemic and antioxidant in rats. Appl Biochem Biotechnol. 2010; 162(2):358-72.

28. Makhlouf H, Saksouk M, Habib J, Chahine R. Determination of antioxidant activity of saffron taken from the flower of Crocus sativus grown in Lebanon. African Journal of Biotechnology. 2011;10(41):8093-100

29. Ochiai T, Ohno S, Soeda S, Tanaka H, Shoyama Y, Shimeno H. Crocin prevents the death of rat pheochromyctoma (PC-12) cells by its antioxidant effects stronger than those of [alpha]-tocopherol. Neurosci Lett. 2004:362 (1):61-64.

30. Papandreou MA, Kanakis CD, Polissiou MG, Efthimiopoulos $S$, Cordopatis $P$, Margarity $\mathrm{M}$, et al. Inhibitory activity on amyloid-beta aggregation and antioxidant properties of Crocus sativus stigmas extract and its crocin constituents. Agric Food Chem. 2006;54(23):8762-8.

31. Hosseinzadeh $\mathrm{H}$, Younesi HM. Anti-nociceptive and anti-inflammatory effects of Crocus sativus L. stigma and petal extracts in mice. BMC Pharmacol. 2002;2(1):1-8

32. Tamaddonfard E, Farshid AA, Eghdami K, Samadi F, Erfanparast A. Comparison of the effects of crocin, safranal and diclofenac on local inflammation and inflammatory pain responses induced by carrageenan in rats. Pharmacol Rep. 2013;65(5):1272-80

33. Vahidi H, Kamalinejad M, Sedaghati N. Antimicrobial Properties of Crocus sativus L. Iranian Journal of Pharmaceutical Research. 2002;1:33-5.

34. Muzaffar S, Rather SA, Khan KZ. In vitro bactericidal and fungicidal activities of various extracts of saffron (Crocus sativus L.) stigmas from Jammu and Kashmir, India. Cogent Food and Agriculture. 2016;2(1):1158999

35. Gandomi H, Misaghi A, Abbaszadeh S, Azami L, Shariatifar N, Tayyar N. Antibacterial effect of aqueous and alcoholic extracts from petal of saffron (Crocus sativus) on some foodborne bacterial pathogens. J Med Plants. 2012;11:189-96.

36. Omidi A, Riahinia N, Montazer TM, Behdani M. Hepatoprotective effect of Crocus sativus (saffron) petals extract against acetaminophen toxicity in male Wistar rats. Avicenna J Phytomed. 2014;4(5):330-6.

37. Shati AA, Alamri SA. Role of saffron (Crocus sativus L.) and honey syrup on aluminum-induced hepatotoxicity. Saudi Med J. 2010;31(10):1106-13

38. Lari P, Abnous K, Imenshahidi M, Rashedinia M, Razavi M, Hosseinzadeh $\mathrm{H}$. Evaluation of diazinon-induced hepatotoxicity and protective effects of crocin Toxicol Ind Health. 2015;31(4):367-76

39. Naghizadeh B, Boroushaki MT, Vahdati MN, Mansouri MT. Protective effects of crocin against cisplatin-induced acute renal failure and oxidative stress in rats. Iran Biomed J. 2008;12(2):93-100.

40. Boroushaki MT, Mofidpour H, Sadeghnia H. Protective effect of safranal against hexachlorobutadiene-induced nephrotoxicity in rat. Iran J Med Sci. 2007;32:173-6.

41. Boroushaki MT and Sadeghnia HR. Protective effect of safranal against gentamicin-induced nephrotoxicity in rat. Ir. J. Med. Sci. 2009;34:285-8.

42. Mehdizadeh R, Parizadeh MR, Khooei AR, Mehri S, Hosseinzadeh H: Cardioprotective Effect of Saffron Extract and Safranal in Isoproterenol-Induced Myocardia Infarction in Wistar Rats. Iran J Basic Med Sci. 2013;16(1):56-63.

43. Razavi BM, Hosseinzadeh $H$, Movassaghi AR, Imenshahidi M, Abnous K. Protective effect of crocin on diazinon induced cardiotoxicity in rats in subchronic exposure. Chem Biol Interact. 2013;203(3):547-55

44. Razavi BM, Hosseinzadeh H, Abnous K, Imenshahidi M. Protective effect of crocin on diazinon induced vascular toxicity in subchronic exposure in rat aorta ex-vivo. Drug Chem Toxicol. 2014;37(4):378-83.

45. Goyal SN, Arora S, Sharma AK, Joshi S, Ray R, Bhatia J, et al. Preventive effect of crocin of Crocus sativus on hemodynamic, biochemical, histopathological and ultra stuctural alterations in isoproterenol-induced cardiotoxicity in rats. Phytomedicine. 2010;17(3-4):227-32.

46. Chahine N, Hanna J, Makhlouf H, Duca L, Martiny L, Chahine R. Protective effect of saffron extract against doxorubicin cardiotoxicity in isolated rabbit heart. Pharm Biol. 2013;51(12):1564-71

47. Mehri S, Abnous K, Mousavi SH, Shariaty VM, Hosseinzadeh H. Neuroprotective effect of crocin on acrylamide-induced cytotoxicity in PC12 cells. Cell Mol Neurobiol. 2012;32(2):227-35

48. Purushothuman S, Nandasena C, Peoples CL, El Masri N, Johnstone DM, Mitrofanis $\mathrm{J}$, et al. Saffron pre-treatment offers neuroprotection to nigral and retinal dopaminergic cells of MPTP-treated mice. J Parkinsons. Dis. 2103;3(1):77-83

49. Geromichalos GD, Lamari FN, Papandreou MA, Trafalis DT, Margarity M, Papageorgiou A, et al. Saffron as a source of novel acetylcholinesterase inhibitors: molecular docking and in vitro enzymatic studies. J Agric Food Chem. 2012;60(24): 6131-8.

50. Khalili M, Hamzeh F. Effects of active constituents of Crocus sativus L. crocin on streptozocin-induced model of sporadic Alzheimer's disease in male rats. Iran Biomed J. 2010;14(1-2):59-65.

51. Mohajeri D, Amouoghli TB, Mousavi Gh, Mesgari M. Antidiabetic activity of Crocus sativus L. (saffron) stigma ethanolic extract in alloxan-induced diabetic rats. Res. J. Biol. Sci. 2008;3(9):1102-8.

52. Samarghandian S, Azimi-Nezhad M, Samini F. Ameliorative effect of saffron aqueous extract on hyperglycemia, hyperlipidemia, and oxidative stress on diabetic encephalopathy in streptozotocin induced experimental diabetes mellitus. Biomed. Res. Int. 2014; 2014: 920857.

53. Kianbakht S, Hajiaghaee R: Anti-hyperglycemic effects of saffron and its active constituents, crocin and safranal, in alloxan-induced diabetic rats. J Med Plants. 2011;3(39):82-9

54. Rajaei Z, Hadjzadeh MA, Nemati H, Hosseini M, Ahmadi M, Shafiee S. Antihyperglycemic and antioxidant activity of crocin in streptozotocin-induced diabetic rats. J. Med. Food. 2013;16(3):206-10

55. Elgazar FA, Rezq AA, Bukhari MH. Anti-Hyperglycemic Effect of Saffron Extract in Alloxan-Induced Diabetic Rats. Eur. J. Biol. Sci. 2013;5(1):14-22.

56. Kianbakht S, Hashem DF. Anti-obesity and anorectic effects of saffron and its constituent crocin in obese Wistar rat. J Med. Plants. 2015;1(53):25-33.

57. Mashmoul M, Azlan A, Yusof BN, Khaza'ai H, Mohtarrudin N, Boroushaki MT. Effects of saffron extract and crocin on anthropometrical, nutritional and lipid profile parameters of rats fed a high fat diet. J Funct. Foods. 2014;8:180-7.

58. Hosseinzadeh $H$, Ziaee $T$, Sadeghi A. The effect of saffron, Crocus sativus stigma, extract and its constituents, safranal and crocin on sexual behaviors in normal male rats. Phytomedicine. 2008;15(6-7):491-5.

59. Pitsikas N, Boultadakis A, Georgiadou G, Tarantilis PA, Sakellaridis N. Effects of the active constituents of Crocus sativus $L$, crocins, in an animal model of anxiety. Phytomedicine. 2008;15(12):1135-9

60. Hosseinzadeh H, Noraei NB. Anxiolytic and hypnotic effect of Crocus sativus aqueous extract and its constituents, crocin and safranal, in mice. Phytother Res. 2009;23(6):768-74

61. Kianbakht S, Ghazavi A. Immunomodulatory effects of saffron: a randomized double-blind placebo-controlled clinical trial. Phytother Res. 2011;25(12):1801-5.

62. Babaei A, Arshami J, Haghparast A, Daneshmesgharan M. Effects of saffron (Crocus sativus) petal ethanolic extract on hematology, antibody response, and spleen histology in rats. Avicenna J Phytomed. 2014;4(2):103-9.

63. Xuan B, Zhou YH, Li N, Min ZD, Chiou GC. Effects of crocin analogs on ocular blood flow and retinal function. J Ocul Pharmacol Ther. 1999;15(2):143-52.

64. Hosseinzadeh $\mathrm{H}$, Talebzadeh F. Anticonvulsant evaluation of safranal and crocin from Crocus sativus in mice. Fitoterapia. 2005;76(7-8):722-4.

65. Rahmani AH, Aly SM. Nigella sativa and its active constituents thymoquinone shows pivotal role in the diseases prevention and treatment. Asian J Pharm Clin Res. 2015; 8(1):48-53

66. Rahmani AH, Al-Zohairy MA, Aly SM, Khan MA. Curcumin: A potential candidate in prevention of cancer via modulation of molecular pathways. Biomed. Res. Int 2014,761608

67. Rahmani AH, Aldebasi $\mathrm{YH}$. Potential role of carica papaya and their active constituents in the prevention and treatment of diseases. Int J Pharm Pharm Sci. 2016;8:11-15

68. Nair SC, Pannikar B, Panikkar KR. Antitumour activity of saffron (Crocus sativus). Cancer Lett. 1991;57(2):109-14.

69. Magesh V, Singh JP, Selvendiran K, Ekambaram G, Sakthisekaran D: Antitumour activity of crocetin in accordance to tumor incidence, anti-oxidant status, drug metabolizing enzymes and histopathological studies. Mol Cell Biochem. 2006;287(1);127-35

70. Feizzadeh B, Afshari JT, Rakhshandeh H, Rahimi A, Brook A, Doosti H. Cytotoxic effect of saffron stigma aqueous extract on human transitional cell carcinoma and mouse fibroblast. Urol J. 2008;5(3):161-7.

71. Salomi MJ, Nair SC, Panikkar KR. Inhibitory effects of Nigella sativa and saffron (Crocus sativus) on chemical carcinogenesis in mice. Nutr Cancer. 1991;16(1):67-72

72. Aung HH, Wang CZ, Ni M, Fishbein A, Mehendale SR, Xie JT, et al. Crocin 
from Crocus sativus possesses significant anti-proliferation effects on human colorectal cancer cells. Exp Oncol. 2007;29(3):175-80.

73. Wang CJ, Shiah HS, Lin JK. Modulatory effect of crocetin on aflatoxin B1 cytotoxicity and DNA adduct formation in C3H10T1/2 fibroblast cell. Cancer Lett. 1991;56(1):1-10

74. Noureini SK, Wink M. Antiproliferative effects of crocin in HepG2 cells by telomerase inhibition and hTERT down-regulation. Asian Pac J Cancer Prev. 2012;13(5):2305-9

75. D’Alessandro AM, Mancini A, Lizzi AR. Crocus sativus stigma extract and its major constituent crocin possess significant antiproliferative properties against human prostate cancer. Nutr Cancer. 2013;65(6):930-42.

76. Das I, Das S, Saha T. Saffron suppresses oxidative stress in DMBA-induced skin carcinoma: a histopathological study. Acta Histochem. 2010;112(4):317-27.

77. Samarghandian S, Borji A, Farahmand SK, Afshari R, Davoodi S. Crocus sativus $\mathrm{L}$. (saffron) stigma aqueous extract induces apoptosis in alveolar human lung cancer cells through caspase-dependent pathways activation. Biomed Res Int. 2013; 2013: 417928

78. Sun $Y, X u H J$, Zhao $Y X$. Crocin exhibits antitumor effects on human leukemia $\mathrm{HL}-60$ cells in vitro and in vivo. Evid Based Complement Alternat Med. 2013; 690164

79. Bakshi H, Sam S, Rozati R, Sultan P, Islam T, Rathore B, et al. DNA fragmentation and cell cycle arrest: a hallmark of apoptosis induced by crocin from kashmiri saffron in a human pancreatic cancer cell line. Asian Pac J Cancer Prev. 2010;11(3):675-9

\section{GRAPHICAL ABSTRACT}

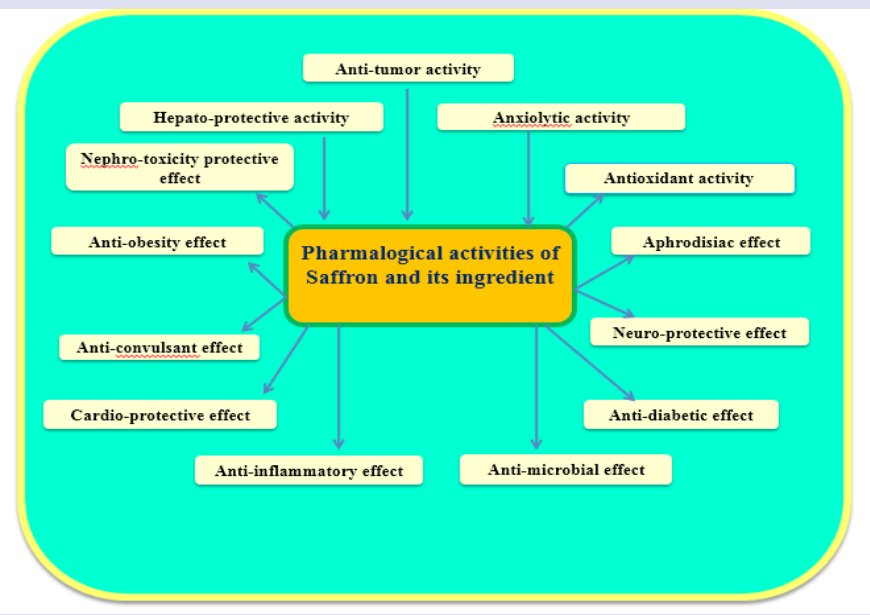

\section{SUMMARY}

- $\quad$ Crocus sativus is a member of iridaceae family and its use in health management is in practice since ancient time.

- $\quad$ Saffron stigma is mixture of valuable components including crocin, crocetin and safranal.

- Research based on clinical trials and animal models have advocates its role in health management without any severe adverse complications.

- Additionally, it also shows role in tumour management through modulation of cell signaling pathways.

\section{ABOUT AUTHORS}

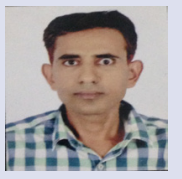

Dr. Arshad Husain Rahmani: is working as an Assistant Professor in the Department of Medical Laboratories, College of Applied Medical Sciences, Qassim University, Kingdom of Saudi Arabia. His research interests include measurement of the therapeutic potential of natural compounds in the management of diseases and expression pattern of the genes linked to cancer development and progression. Currently he is working on research projects funded by Research Scientific Deanship, Qassim University and National Science Technology Innovation Program of Ministry of Education (NSTIP), Saudi Arabia. He has published more than 37 research and review article, of international repute. Besides this, he is an active reviewer of several ISI /Pubmed indexed journals.

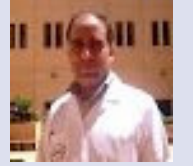

Dr. Amjad Ali Khan: Is currently working as an assistant professor in the Department of basic health science, College of Applied Medical Sciences, Qassim University, Saudi Arabia. He is actively involved in academics and research activities. Besides this, he is interested in research activities like antioxidant role of different medicinal plant extracts and their anti diabetic properties. In addition, the author as a team member is involved in research activities related to cancer induction and expression analysis of different sub cellular pathways.



Yousef Homood Aldebasi: Is Professor of Optometry and the Dean of College of Applied Medical Sciences, Qassim University, Saudi Arabia. His research interests include vision sciences and implications of natural compounds in the prevention and treatment of diabetic retinopathy. He is involved on various research projects funded by Research Scientific Deanship, Qassim University and National Science Technology Innovation Program of Ministry of Education (NSTIP), Saudi Arabia. He has published more than 50 research and review article in international repute journal and presented several papers in national level and international level.

Cite this article: Rahmani AH, Khan AA, Aldebasi YH. Saffron (Crocus sativus) and its Active Ingredients: Role in the Prevention and Treatment of Disease. Pharmacog J. 2017;9(6):873-9. 